\title{
ORIGINAL ARTICLE \\ Sufficient iodine status among Norwegian toddlers 18 months of age - cross-sectional data from the Little in Norway study
}

\author{
Inger Aakre'*, Maria Wik Markhus', Marian Kjellevold', Vibeke Moe², Lars Smith² and \\ Lisbeth Dahl' \\ 'Food Security and Nutrition, Institute of Marine Research, Bergen, Norway; ${ }^{2}$ Department of Psychology, University of \\ Oslo, Oslo, Norway
}

Abstract

Background: Inadequate iodine intake has been identified in several population groups in the Nordic countries over the past years; however, studies of iodine status in infants and toddlers are scarce.

Objective: The aim of this study is to evaluate the iodine status and dietary iodine sources among 18-monthold toddlers from Norway.

Methods: Cross-sectional and country representative data from the Little in Norway study were used. All children who had given a spot urine sample at 18 months age were included $(n=416)$. Urinary iodine concentration (UIC) was determined by inductively coupled plasma mass-spectrometry. Dietary habits and supplement use were measured by a food frequency questionnaire.

Results: Median (25th-75th percentiles [p25-p75]) UIC was 129 (81-190) $\mu \mathrm{g} / \mathrm{L}$ while estimated median (p25p75) habitual iodine intake was 109 (101-117) $\mu \mathrm{g} /$ day. None of the children were below the estimated average requirement (EAR) of $65 \mu \mathrm{g} /$ day or above the upper intake level of $180 \mu \mathrm{g} / \mathrm{day}$. There were no differences in either UIC or estimated habitual iodine intake between different geographic areas in Norway. Milk was the most important iodine source, contributing an estimated $70 \%$ to the total iodine intake, while other foods rich in iodine such as seafood and enriched baby porridge contributed about $30 \%$.

Conclusions: The iodine status among 18-month-old toddlers from different geographic areas in Norway was sufficient, indicated by a median UIC above the WHO cutoff of $100 \mu \mathrm{g} / \mathrm{L}$. This was further supported by the estimated habitual iodine intake, where none of the participants were below the EAR. Milk was an important iodine source in this age group; thus children with a low intake might be at risk of insufficient iodine intake.

Keywords: Iodine; Urinary iodine concentration; Iodine intake; Dietary iodine intake; Toddlers

Received: 29 May 20 18; Revised: 28 August 20 8; Accepted: 18 September 20 18; Published: 25 October 2018

I nfants and toddlers are particularly vulnerable to inadequate iodine nutrition, as iodine is crucial for optimal child growth and development $(1,2)$ through the many functions of the thyroid hormones $(3,4)$. Thus, iodine deficiency has been pointed out as one of the main factors that prevent children from achieving their developmental potential (5). Even though the global work towards eliminating iodine deficiency disorders has been successful $(6,7)$, iodine deficiency has been reemerging in Europe (8); and inadequate iodine status has been reported in several European countries during recent years (9-12).

Iodine is present in relatively few food groups, and iodized salt is the most important source globally (13). In Norway, the permitted iodine level of $5 \mu \mathrm{g} / \mathrm{g}$ in table salt is too low to be considered a significant iodine source in the population (9). However, animal feed is enriched with iodine in Norway; therefore milk, dairy products, and eggs have significant levels of iodine. Marine fish, especially lean fish such as cod, haddock, and saithe, and fish products also have high levels of iodine $(14,15)$. Industrymanufactured baby food is enriched with iodine; thus among toddlers this is an important iodine source as well as breast milk or formula (16). Dietary surveys among Norwegian toddlers revealed that only $35 \%$ and $4 \%$ were still breastfed at 12 (17) and 24 months of age (18), respectively. Young children in the weaning period are therefore dependent on iodine-rich complementary foods in order to reach an intake of $50-70 \mu \mathrm{g} /$ day as recommended in the Nordic countries (19). 
As the consumption of milk, yoghurt, and lean fish has been declining in Norway, recent studies have reported insufficient iodine status among pregnant and lactating women (20-23). An association between insufficient iodine intake in pregnant Norwegian women and poorer developmental status in children at 3 years of age has also been found (24). Infants and young children have therefore been identified as a vulnerable group regarding insufficient iodine intake. Recently published data among 5 -year-old preschool children $(n=220)$ and 3-9-year-old children $(n=47)$ showed iodine sufficiency in these groups, with a median urinary iodine concentration (UIC) of 132 and $148 \mu \mathrm{g} / \mathrm{L}$, respectively $(25,26)$. Studies among infants and toddlers remain scarce; however, iodine status was measured in a study of Norwegian toddlers under the age of 2 with cow's milk protein allergy. This study found a median UIC of $159 \mathrm{ug} / \mathrm{L}$, indicating sufficient iodine status (27). The main objective of this paper is to assess iodine status in toddlers 18 months of age participating in the Little in Norway study (LiN). To our knowledge, this is the first paper from Norway to present data on iodine status and its relation to dietary habits among healthy children less than 2 years of age.

\section{Subjects and methods}

\section{Study design and subjects}

This paper is based on data from the LiN project (ISRCTN registry number 66710572), a prospective population-based cohort study conducted between September 2011 and November 2014. The study was established to investigate pre- and postnatal risk factors influencing child development from pregnancy to 18 months of age. Pregnant women at nine primary health clinics across all four Norwegian health regions were recruited. The data collection included questionnaires completed by the mothers and biological samples of mother and child. In total, 1,036 pregnant women consented to participate in the LiN cohort. In this paper, cross-sectional data from toddlers 18 months of age were used, as well as background characteristics of their mothers at study enrollment. Of the 1,036 participating pregnant women, 777 children were still participating at 18 months age. Not all toddlers were able to give a urine sample at the time of data collection and some failed due to technical issues. Thus, the final sample size consisted of 416 toddlers 18 months of age, along with their mothers. Further details regarding study attrition for the participants have been described elsewhere (28).

\section{Urinary iodine concentration}

UIC was assessed in spot urine samples from the children using Uricol collection pack (Sterisets International B.V., SteriSets GP Supplies, Newcastle Urine Collection
Pack, UK). The urine was extracted from the pad with a syringe and transferred to CryoTubes (CryoTubes ${ }^{\mathrm{TM}}$ Vials, Nunc A/S, Roskilde, Denmark) for storage at $-18^{\circ} \mathrm{C}$ pending analysis. Content of iodine in urine was determined by inductively coupled plasma mass-spectrometry at the Institute of Marine Research in Norway. Further description of the analytic method and accuracy has been published elsewhere (23).

\section{Estimated habitual iodine intake}

The children's habitual food intake was mapped by the mothers of the children answering questions about average intake of selected food items and dishes through an online questionnaire. There were 13 questions concerning the general diet, of which nine questions concerned iodine-containing food items, where intake of yoghurt, porridge, fish, and fish products was assessed. Frequency responses were recorded as never/rarely to seven times per week or more. There was one question assessing intake of eggs, where the frequency responses ranged from less than one egg per week to eight or more per week. There were nine questions assessing intake of fats and oils, of which questions regarding margarine and butter were relevant for iodine intake. The frequency responses ranged from never to daily. There was one question regarding breast milk intake at 18 months of age, where the frequency responses ranged from once in the last $24 \mathrm{~h}$ to 10 times or more. However, there were no data available from Norway regarding the amount of breast milk consumed among 18-month-old children. Nor has data regarding breast milk intake been registered in the national dietary surveys for 1 - and 2-year-old children in Norway $(17,18)$. Therefore, children still breastfed at 18 months were excluded from the iodine intake estimations. The intake frequencies related to yoghurt, porridge, fish/fish products, eggs, and butter/ margarine were converted to daily amounts using data from a national nutrition survey among children 2 years of age (18) and multiplied with the iodine concentration for each food item or dish. In all calculations, iodine content reported in the Norwegian Food Composition Table (29) was used. The questionnaire did not contain intake of milk and cheese, which are important dietary iodine sources in Norway. Mean intake of milk, white cheese/cheese spread and brown cheese/whey cheese spread among Norwegian 2-year-olds, both users and non-users of the food, was used to calculate the iodine contribution from these foods. In total, milk and cheese were estimated to contribute 79 $\mu \mathrm{g} / \mathrm{day}$, which was applied in the estimation of daily iodine intake among all non-breastfed children.

The frequency responses of the major iodine-contributing foods - fish, yoghurt, and porridge - were divided into low/medium consumption and high consumption using the following criteria: high consumption of fish: lean fish or fish products for dinner at least two to three 
times per week and fish (fatty and lean) as bread topping at least four to six times per week; high consumption of yoghurt: at least four to six times per week; high consumption of fish and yoghurt: both intake of fish and yoghurt was high; high consumption of porridge: (homemade or industry manufactured) at least four to six times per week.

\section{Definitions of iodine status and iodine intake}

The epidemiological criteria for assessing iodine nutrition based on median UIC for children were used in this study (13). For children less than 2 years of age a median UIC $<100 \mu \mathrm{g} / \mathrm{L}$ indicates insufficient iodine status, while a median UIC $\geq 100$ indicates adequate iodine status. In the Nordic Nutrition Recommendations, an iodine intake of $50-70 \mu \mathrm{g} /$ day is estimated to be sufficient for infants and children $<2$ years of age (19). However, as the Nordic Nutrition Recommendations does not have an average requirement for young children, the estimated average requirement (EAR) from the US Institute of Medicine of $65 \mu \mathrm{g} /$ day was used for evaluating the habitual iodine intake from food (30). To assess excessive iodine intakes, the World Health Organization's (WHO) upper intake level (UL) of $180 \mu \mathrm{g} /$ day for children under 2 years was used (31).

\section{Background characteristics and anthropometry}

The mothers answered a precoded questionnaire concerning background variables for themselves and their children. The WHO body mass index (BMI) $\left(\mathrm{kg} / \mathrm{m}^{2}\right)$ was used to classify underweight, normal weight, overweight, and obesity, defined by BMI $<18.5 \mathrm{~kg} / \mathrm{m}^{2}$, BMI $=18.5-$ $24.9 \mathrm{~kg} / \mathrm{m}^{2}, \mathrm{BMI}=25.0-29.9 \mathrm{~kg} / \mathrm{m}^{2}$, and $\mathrm{BMI} \geq 30 \mathrm{~kg} / \mathrm{m}^{2}$, respectively (32). The children's height and weight were registered at the primary health clinic by trained health personnel. The gender-specific $z$-scores height-for-age, weight-for-age, weight-for-height (WHZ), and BMI-forage (BMIz) were calculated using the WHO macro for SPSS $(33,34)$. A child was categorized as undernourished if $\mathrm{WHZ}$ or BMIz, was $<-2$, and overweight if $\mathrm{WHZ}$ or BMIz was above 2 .

\section{Ethics}

Ethics approval for the survey was given by the Regional Committees for Medical Research Ethics (2011/560 REK Sør-Øst). Written informed consent was provided by the mothers on behalf of themselves and their children. All aspects of the study agreed with the latest version of the Helsinki Declaration.

\section{Statistics}

Normally distributed data were presented as mean \pm SD. Non-normally distributed data were presented as median and 25th-75th percentiles (p25-p75). Due to the skewed distribution, non-parametric tests were used for two-sided tests of differences between groups (Mann-Whitney $\mathrm{U}$ test). The UIC among children was used as dependent variable in linear regression analyses. Because of skewed distribution, UIC was log2-transformed. Background characteristics (from Table 1) and dietary variables (from Table 4) were assessed for associations in simple linear models. All variables with an association $(p<0.20)$ were selected for the preliminary multiple model, which included the following: iodine supplements during pregnancy, high consumption of fish, high consumption of fish and yoghurt, high consumption of porridge. By backwards stepwise selection conducted manually, variables with a significant association at $p \leq 0.05$ were included in the final model. Analysis of the residuals was performed to examine the fit of the model.

\section{Results}

Background characteristics of mothers and toddlers are presented in Table 1. The distribution of participants between different geographic regions in Norway was quite even. Mean age among the mothers was 30 years, and $82 \%$ had higher education at university level. The gender distribution among the toddlers was even, with $52 \%$ boys and $48 \%$ girls. Almost $10 \%$ of the toddlers were still breastfed, $67 \%$ had received breast milk previously, while $4.6 \%$ had never been breastfed. Only 0.7 and $5.3 \%$ were wasted and overweight, respectively, according to weight-for-length $z$-scores. In total, $60.8 \%$ of the toddlers received dietary supplements, and cod liver oil was the most commonly used supplement.

Table 2 presents the UIC among the toddlers in different geographical regions of Norway and across all areas. The median UIC (p25-p75) was $129(81-190) \mu \mathrm{g} / \mathrm{L}$. As indicated by Fig. 1, 34\% had UIC below $100 \mu \mathrm{g} / \mathrm{L}, 59 \%$ had UIC between 100 and $200 \mu \mathrm{g} / \mathrm{L}$ and $7 \%$ had UIC above $300 \mu \mathrm{g} / \mathrm{L}$. There were no significant or substantial differences in UIC between different geographical regions or genders. The children who had never been breastfed had higher median UIC $(149 \mu \mathrm{g} / \mathrm{L})$ than children who were no longer breastfed. The children who were still breastfed had a median UIC of $117 \mu \mathrm{g} / \mathrm{L}$; however the differences in UIC between breastfeeding statuses were not statistically significant. Children who were attending kindergarten had similar median UIC as children who were not attending kindergarten.

Intake frequencies of iodine-rich foods are shown in Table 3. Yoghurt was commonly consumed among the toddlers; however, $22 \%$ were given yoghurt $\leq 1$ time/week. About two-thirds of the children were given porridge, either industry manufactured or homemade $\leq 1$ time/week. About 80,70 , and $80 \%$ of the children were given fatty fish, lean fish, or fish products for dinner $\leq 1$ time/week, respectively. Baby food with fish was not commonly consumed, with $95 \%$ in the category of less than or equal to 
Table 1. Characteristics of Norwegian mothers and toddlers 18 months of age

\begin{tabular}{|c|c|c|c|}
\hline Characteristics of mothers & $(n=416)$ & Characteristics of toddlers & $(n=416)$ \\
\hline Age, years & $30.3 \pm 4.7$ & Boy & $217(52.2)$ \\
\hline $\mathrm{BMI}, \mathrm{kg} / \mathrm{m}^{2 \mathrm{a}}$ & $23.8 \pm 4.5$ & Girl & $198(47.6)$ \\
\hline$<18.5$ & $15(3.6)$ & Never been breastfed & $19(4.6)$ \\
\hline $18.5-24.9$ & $233(56.9)$ & Stopped breastfeeding & $279(67.1)$ \\
\hline$\geq 25$ & IOI (24.3) & Still breastfed & $4 \mid(9.9)$ \\
\hline Education level & & Breastfeeding frequency per $24 \mathrm{~h}^{c}$ & \\
\hline Primary and secondary school & $7(1.7)$ & I time & $6(14.6)$ \\
\hline High school & $67(16.2)$ & $2-3$ times & $25(61.0)$ \\
\hline$<4$ years of university ${ }^{\mathrm{b}}$ & $167(40.1)$ & $\geq 4$ times & $10(24.4)$ \\
\hline$\geq 4$ years of university ${ }^{b}$ & $174(4 \mid .8)$ & Weight-for-length/height, z-score & $0.6 \pm 1.0$ \\
\hline Work situation & & $<-2$ (wasted) & $3(0.7)$ \\
\hline Work full-time & $319(76.7)$ & $>2$ (overweight) & $22(5.3)$ \\
\hline Work part-time & $29(7.0)$ & BMI-for-age, z-score & $0.5 \pm 1.01$ \\
\hline Student & $58(13.9)$ & $<-2$ (underweight) & $5(1.2)$ \\
\hline Unemployed & $9(2.2)$ & $>2$ (overweight) & $21(5.0)$ \\
\hline Geographic region & & Supplement use (all types) weekly & $253(60.8)$ \\
\hline Mid-Norway & $134(32.2)$ & Cod liver oil & I5I (36.3) \\
\hline North Norway & $80(19.2)$ & Vitamin D drops & $84(20.2)$ \\
\hline Western Norway & $89(21.4)$ & Omega-3 & $19(4.6)$ \\
\hline Eastern Norway & $112(26.9)$ & Multivitamin mixture & $40(9.6)$ \\
\hline Use medication for thyroid disorder & $15(3.6)$ & Iron & I (0.2) \\
\hline Used iodine supplements during pregnancy & $91(21.9)$ & Other & $14(3.4)$ \\
\hline
\end{tabular}

Values are presented as mean \pm SD and $n(\%)$.

aBody mass index before pregnancy.

bUniversity or university college.

'Breastfeeding frequency among children still breastfed $(n=4 I)$. Missing values: 67 missing from women's BMl; I missing from mother's education; I missing from geographic area; I missing from use of medication for thyroid disorder; 93 missing from iodine supplements during pregnancy; I missing from tobacco use in pregnancy; I missing from work situation; I missing from gender of child; 77 missing from breastfeeding status; 21 missing from anthropometric measures of children; 90 missing from supplement use in children.

Table 2. Urinary iodine concentration (UIC) among Norwegian toddlers 18 months of age by different geographical regions and characteristics $(n=416)$

\begin{tabular}{|c|c|c|c|c|c|c|}
\hline & \multicolumn{4}{|c|}{ UIC ( $\mu g / L)$} & \multirow[t]{2}{*}{ Min } & \multirow[t]{2}{*}{$\operatorname{Max}$} \\
\hline & Median & p25-p75 & Mean & SD & & \\
\hline Total $(n=416)$ & 129 & $8 I-190$ & 148 & 97 & 8 & 688 \\
\hline \multicolumn{7}{|l|}{ Gender } \\
\hline Boys $(n=217)$ & 139 & $83-258$ & 147 & 95 & 12 & 687 \\
\hline Girls $(n=198)$ & 128 & $75-199$ & 150 & 100 & 8 & 688 \\
\hline \multicolumn{7}{|l|}{ Geographic region } \\
\hline Mid-Norway $(n=134)$ & 125 & $69-186$ & 138 & 83 & 8 & 426 \\
\hline North Norway $(n=80)$ & 136 & $94-195$ & 149 & 83 & 17 & 349 \\
\hline Western Norway $(n=89)$ & 144 & $88-220$ & 170 & 125 & 14 & 688 \\
\hline Eastern Norway $(n=1 \mid 2)$ & 125 & $75-182$ & 143 & 95 & 14 & 515 \\
\hline \multicolumn{7}{|l|}{ Breastfeeding status } \\
\hline Never been breastfed $(n=19)$ & 149 & $76-212$ & 169 & 126 & 24 & 515 \\
\hline Stopped breastfeeding $(n=279)$ & 130 & $74-201$ & 146 & 91 & 8 & 539 \\
\hline Still breastfed $(n=4 \mathrm{I})$ & 117 & $85-188$ & 144 & 87 & 19 & 422 \\
\hline \multicolumn{7}{|l|}{ Kindergarten attendance } \\
\hline Yes $(n=332)$ & $13 \mid$ & $81-190$ & 148 & 94 & 8 & 687 \\
\hline No $(n=68)$ & 126 & $73-195$ & 148 & 114 & 16 & 688 \\
\hline
\end{tabular}

There were no significant differences in UIC between gender $(p=0.46 \mathrm{I})$, geographic areas $(p=0.32 \mathrm{I})$, breastfeeding status $(p=0.854)$, or kindergarten attendance $(p=0,3 \mathrm{II})$ tested by Kruskal-Wallis test/Mann-Whitney $U$ test. 


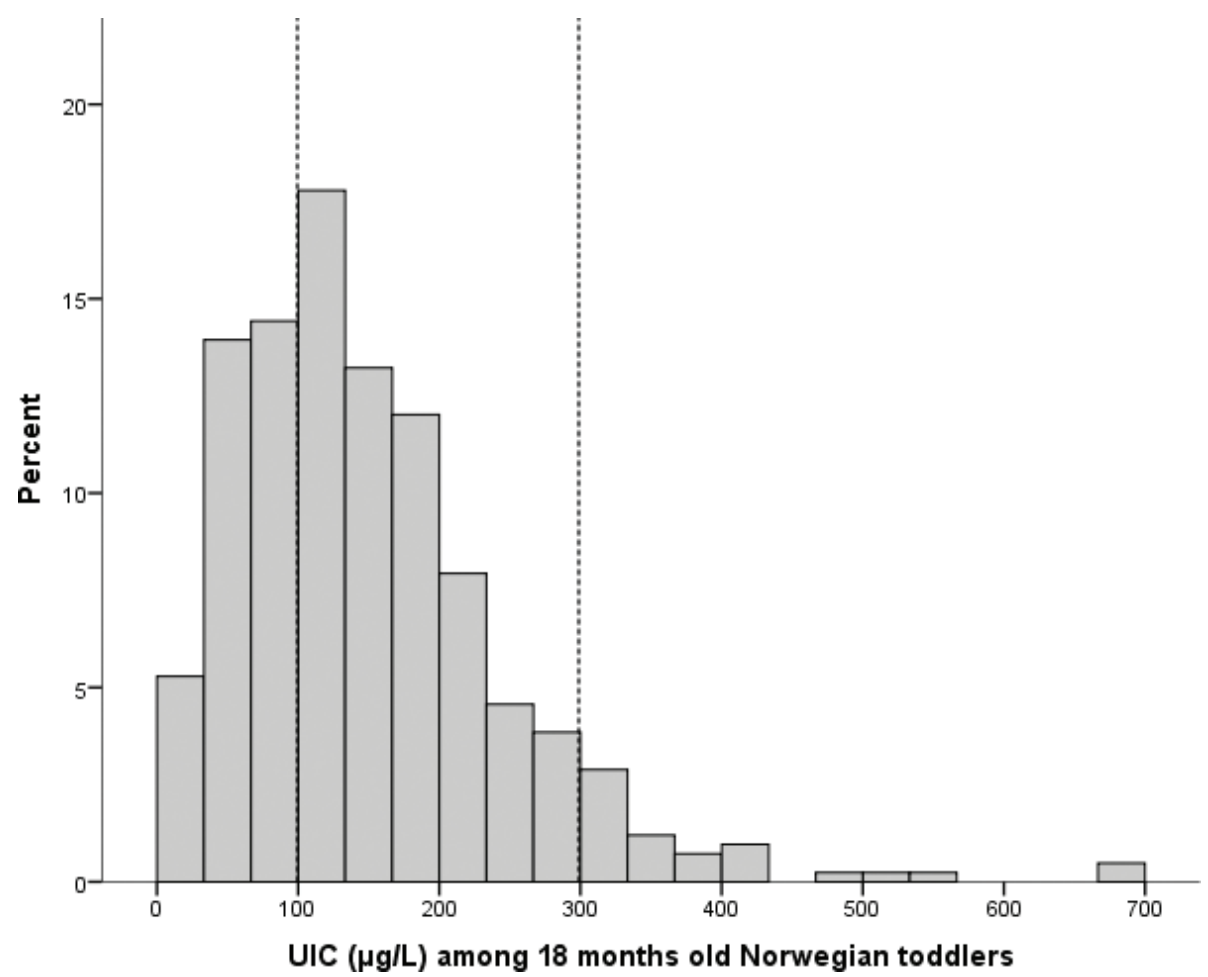

Fig. 1. Distribution of urinary iodine concentration (UIC) among Norwegian children 18 months of age: $33 \%$ had UIC below $100 \mu \mathrm{g} / \mathrm{L}, 59 \%$ had UIC between 100 and $299 \mu \mathrm{g} / \mathrm{L}$, and $7 \%$ had UIC above $300 \mu \mathrm{g} / \mathrm{L}(n=416)$.

Table 3. Frequency of intake (times/week) of iodine-rich foods among Norwegian toddlers 18 months of age $\left(n=340^{\mathrm{a}}\right)$

\begin{tabular}{|c|c|c|c|c|}
\hline \multirow[t]{2}{*}{ lodine-rich foods } & Never/rarely & I time per week & 2-3 times per week & $\geq 4$ times per week \\
\hline & $n(\%)$ & $n(\%)$ & $n(\%)$ & $n(\%)$ \\
\hline Yoghurt & $4 \mid(12)$ & $35(10)$ & $95(28)$ & $169(50)$ \\
\hline $\begin{array}{l}\text { Porridge (industry } \\
\text { manufactured) }\end{array}$ & $193(57)$ & $28(8)$ & $37(11)$ & $82(24)$ \\
\hline Porridge (homemade) & $147(43)$ & $85(25)$ & $62(18)$ & $46(14)$ \\
\hline Fatty fish, dinner & $69(20)$ & $202(59)$ & $67(20)$ & $2(1)$ \\
\hline Lean fish, dinner & $80(19)$ & $221(53)$ & $39(12)$ & 0 \\
\hline Fish products, dinner & $55(16)$ & $225(66)$ & $55(16)$ & $5(2)$ \\
\hline $\begin{array}{l}\text { Baby food with fish (industry } \\
\text { manufactured) }\end{array}$ & $296(87)$ & $28(8)$ & $15(4)$ & I $(0.3)$ \\
\hline Fatty fish, spread & $|7|(50)$ & $64(19)$ & $64(19)$ & $4 \mid(I 2)$ \\
\hline Lean fish, spread & $|4|(42)$ & $78(23)$ & $87(26)$ & $34(10)$ \\
\hline Eggs & $86(32)$ & $96(36)$ & $63(24)$ & $22(8)$ \\
\hline
\end{tabular}

Values given in $n(\%)$ within participants with dietary intake category. ${ }^{a} n=340$ for all foods except eggs where $n=267$.

once a week. Lean fish products such as caviar and fishcakes and fatty fish products such as mackerel or salmon were consumed as bread spread among 31 and 36\% 2-3 times/week or more frequently, respectively, while the rest consumed fish as bread topping $\leq 1$ time/week. Sixty-eight percent consumed eggs less than or equal to once a week.

UIC according to low/medium and high consumption frequencies of iodine-rich foods is shown in Table 4 . There were no substantially or statistically significant differences in UIC between the different consumption categories for any of the foods. There were quite a few children with a high consumption frequency of fish $(20 \%)$. Yoghurt was more frequently consumed, and $50 \%$ had a high intake. Only $12 \%$ had a high frequency in intake of both fish and yoghurt. Industry-manufactured porridge is enriched with iodine in Norway; nevertheless, there were no difference in 
Table 4. Urinary iodine concentration (UIC) among Norwegian toddlers 18 months of age with low/medium consumption frequency and high consumption frequency of iodine-rich foods $(n=340)$

\begin{tabular}{|c|c|c|c|c|}
\hline & \multicolumn{4}{|c|}{ UIC $(\mu g / L)$} \\
\hline & \multicolumn{2}{|c|}{ Low/medium consumption } & \multicolumn{2}{|c|}{ High consumption ${ }^{a}$} \\
\hline & Median (p25-p75) & $n$ & Median (p25-p75) & $n$ \\
\hline Fish & I34 (83-200) & 271 & $117(56-200)$ & 69 \\
\hline Yoghurt & $123(79-200)$ & $|7|$ & $132(75-200)$ & 169 \\
\hline Fish and yoghurt & $|3|(8 \mid-200)$ & 298 & 117 (55-198) & 42 \\
\hline Porridge, industry-manufactured & $129(81-193)$ & 258 & $123(55-208)$ & 82 \\
\hline Porridge, homemade & $129(76-205)$ & 294 & $119(73-185)$ & 46 \\
\hline
\end{tabular}

Values given as median (p25-p75).

${ }^{2}$ Fish: Lean fish or fish products for dinner at least 2-3 times/week, and lean fish or fatty fish as bread topping at least 4-6 times/week. Yoghurt: at least 4-6 times/week. Fish and yoghurt: both intake of fish and yoghurt was high. Porridge (homemade or industry-manufactured): at least 4-6 times/ week. Differences in UIC between consumption frequencies were tested by Mann-Whitney $U$ test for each of the food groups. None were statistically significant.

Table 5. Estimated habitual iodine intake among non-breastfed Norwegian toddlers 18 months of age in different geographical regions of Norway $\left(n=232^{\mathrm{a}}\right)$

\begin{tabular}{|c|c|c|c|c|c|c|}
\hline & \multicolumn{6}{|c|}{ Estimated habitual iodine intake ( $\mu g /$ day) } \\
\hline & Median & p25-p75 & Mean & SD & Min & Max \\
\hline Total $(n=232)$ & 109 & $101-117$ & 110 & 13 & 82 & 157 \\
\hline \multicolumn{7}{|l|}{ Geographic region } \\
\hline Mid-Norway $(n=76)$ & 110 & $101-116$ & 109 & 11 & 90 & 157 \\
\hline North Norway $(n=44)$ & 105 & $97-120$ & 105 & 12 & 84 & 149 \\
\hline Western Norway $(n=5 \mathrm{I})$ & 107 & $101-118$ & 109 & 13 & 82 & 138 \\
\hline Eastern Norway $(n=6 I)$ & 113 & $102-124$ & 114 & 14 & 88 & 145 \\
\hline
\end{tabular}

a 49 missing from dietary data and 35 excluded as they were still breastfed. lodine intake from milk and cheese have been estimated based on data from 2-year-old children (18) and were estimated to contribute $79 \mu \mathrm{g}$ iodine/day.

median UIC between the group who received homemade porridge and those who received industry-manufactured porridge.

All the dietary variables among children included in Table 4, as well as background characteristics of the mothers and children, were tested for associations in linear regression models. None of the food consumption variables or background characteristics for mothers or children had a significant association with the children's UIC. Table 5 shows the estimated habitual iodine intake from the main dietary iodine sources (yoghurt, milk, cheese, fish/fish products, porridge, eggs, butter/margarine) among non-breastfed children 18 months of age in Norway. Estimated median (p25-p75) habitual iodine intake was 109 (101-117) $\mu \mathrm{g} / \mathrm{day}$ for all children across geographic regions (where the estimated iodine contribution from milk and cheese is included). There was no substantial difference in estimated habitual iodine intake between the different geographic regions. None of the children were below the EAR ( $65 \mu \mathrm{g} / \mathrm{day})$ or above the $\mathrm{UL}(180 \mu \mathrm{g} /$ day $)$. Estimated iodine intake from milk and cheese contributed about $72 \%$ of the total iodine mean intake, while fish contributed about $12 \%$ and other foods about $16 \%$.

\section{Discussion}

The Norwegian toddlers in this study had adequate iodine status, as indicated by a median UIC of $129 \mu \mathrm{g} / \mathrm{L}$, which is above the WHO cutoff of $100 \mu \mathrm{g} / \mathrm{L}$. This finding was supported by the estimated habitual iodine intake, which was $109 \mu \mathrm{g} /$ day. None of the children had an estimated habitual iodine intake below the EAR of $65 \mu \mathrm{g} /$ day or above the UL of $180 \mu \mathrm{g} /$ day. There were no substantial differences in either UIC or iodine intake between different geographic areas of Norway. These findings are in line with the local small-scale Norwegian studies among toddlers with cow's milk protein allergy and young children presented in the introduction (25-27).

Infant formula is enriched with iodine in Norway, and the average iodine content of several products of prepared formula intended for consumption from 6 months age, using data from the food composition 
table, is $15 \mu \mathrm{g} / 100 \mathrm{~g}$ (29). A recent study among lactating Norwegian women found that the median iodine concentration in breast milk was $68 \mu \mathrm{g} / \mathrm{L}(7 \mu \mathrm{g} / 100 \mathrm{~g})(20)$, about half of the iodine content found in formula. The children who were never breastfed might still receive formula at 18 months of age, which could explain why the median UIC was highest in this group. A correlation with UIC and use of infant formula has been reported by others $(35,36)$. Similar results to ours were also found in the mentioned study of 57 infants under the age of 2 with cow's milk protein allergy, where the breastfed children had lower UIC than the children who received formula or were weaned (27).

Intake of milk, formula, and cheese was not recorded in this study, which is a major limitation to the dietary data, as milk is an important component in the diet of young Norwegian children $(17,18)$. In our study, yoghurt was the most frequently consumed iodine-rich food. Fish and fish products were not as frequently consumed and about $52 \%$ consumed fish or fish products (all types) for dinner no more than once a week and $42 \%$ as bread spread no more than once a week (data not shown). Similar results were found in a Norwegian study among preschool children (4-6 years of age); however, the consumption of fish as bread spread was higher than in our study (26). Portion sizes were not registered in this study; however data from all the Nordic countries suggest that fish consumption is generally low among preschool children, including Norway (37). This is in line with our findings, where the majority had an intake below the recommendation for 2-year-old children (38). We did not find any substantial difference in UIC between different consumption frequencies of yoghurt, fish, porridge, or eggs, which was in line with the findings from the regression model where none of the dietary intake variables were associated with UIC. This suggests that milk probably made a large contribution to the total iodine intake among the children in this study. Milk as an important contributor to young children's iodine status in Norway has also been found by others (25). Recent studies suggest that pregnant and lactating women in Norway have mild to moderate iodine deficiency (20-23). Others have also found adequate iodine status among children, while mothers from the same population were iodine deficient (39-41). In line with our findings, this has been suggested to be caused by a relatively higher consumption of milk among children $(25,39)$. On the other hand, as pointed out by Trøan et al., children with a high milk consumption may be at risk of excessive iodine intakes in Norway as the iodine content of milk is relatively high (42).

The median estimated habitual iodine intake was lower than the median UIC. There are several challenges related to dietary assessment, in addition to the mentioned limitation of using extrapolated intake values for milk and cheese. Only the main dietary iodine-containing food items were included in the estimated habitual intake, and missed sources (e.g. vegetables, meat, and bread) cannot be ruled out. Portion sizes from a national survey among 2-year-old children were used. As dietary habits rapidly change in the weaning period (43), the portion sizes may not be accurate for toddlers 18 months of age. Also, most toddlers in this study were attending kindergarten $(79.8 \%$, data not shown), which may further complicate dietary assessment as the parents have less control of food consumption. Nevertheless, the estimated habitual iodine intake indicated sufficient iodine status in this age group, which was in line with the WHO epidemiological criteria for assessing iodine nutrition by median UIC. Further, the estimated habitual iodine intake allows one to assess the iodine status at an individual level, as opposed to the UIC, which provides valuable information. None of the children had an estimated iodine intake below the EAR or above the UL.

\section{Conclusion}

Iodine is a crucial nutrient during the first 1,000 days of life (44), and children under 2 years of age have been identified as a particularly vulnerable group for inadequate iodine intake by the WHO (31). Thus, the iodine status among young children should be carefully monitored. This study showed that the iodine status among 18-month-old toddlers was sufficient. Further, milk seemed to be the major iodine-contributing food item among these children, and the intake of fish and enriched porridge was low. Children with low intake of milk could therefore potentially be at risk of insufficient iodine intake in Norway.

\section{Acknowledgements}

We are grateful to all the families that participated in the Little in Norway study and all research assistants at the public health clinics. A special warm thanks to Unni Tranaas Vannebo for her positive and enthusiastic engagement in organizing the project data collection. Thanks to Anne Karin Syversen for taking care of all the collected biological samples and to Tonja Lill Eidsvik and Berit Solli for technical assistance with the laboratory work. The Research Council of Norway (grant number 196156) and the Norwegian Seafood Research Fund, FHF (grant number 900842) supported the work.

\section{Conflict of interest and funding}

The authors declare no conflict of interest. The Research Council of Norway (grant number 196156) and the Norwegian Seafood Research Fund, Fiskeri og Havbruksnæringens Forskningsfond (grant number 900842) supported the work. 


\section{References}

1. Zimmermann MB, Jooste PL, Pandav CS. Iodine-deficiency disorders. Lancet 2008; 372(9645): 1251-62. https://doi.org/ 10.1016/S0140-6736(08)61005-3.

2. Zimmermann BM. The role of iodine in human growth and development. Semin Cell Dev Biol 2011; 22(6): 645-52. https:// doi.org/10.1016/j.semcdb.2011.07.009.

3. Brent GA. Mechanisms of thyroid hormone action. J Clin Invest 2012; 122(9): 3035-43. https://doi.org/10.1172/JCI60047

4. Bernal J. Thyroid hormones and brain development. Vitam Horm 2005; 71: 95-122. https://doi.org/10.1016/S0083-6729(05) 71004-9.

5. Walker SP, Wachs TD, Grantham-McGregor S, Black MM, Nelson CA, Huffman SL, et al. Inequality in early childhood: risk and protective factors for early child development. Lancet 2011; 378(9799): 1325-38. https://doi.org/10.1016/ S0140-6736(11)60555-2.

6. Andersson M, Karumbunathan V, Zimmermann MB. Global iodine status in 2011 and trends over the past decade. J Nutr 2012; 142(4): 744-50. https://doi.org/10.3945/jn.111.149393.

7. IGN. Iodine Global Network, 2016. Annual Report. Zürich, Switzerland: Iodine Global Network; 2016.

8. Lazarus JH. Iodine status in Europe in 2014. Eur Thyroid J 2014; 3(1): 3-6. https://doi.org/10.1159/000358873.

9. Nyström HF, Brantsæter AL, Erlund I, Gunnarsdottir I, Hulthén L, Laurberg P, et al. Iodine status in the Nordic countries - past and present. Food Nutr Res 2016; 60(1): 31969. https://doi.org/10.3402/fnr.v60.31969.

10. Bath SC, Steer CD, Golding J, Emmett P, Rayman MP. Effect of inadequate iodine status in UK pregnant women on cognitive outcomes in their children: results from the Avon Longitudinal Study of Parents and Children (ALSPAC). Lancet 2013; 382(9889): 331-7. https://doi.org/10.1016/S0140-6736(13)60436-5.

11. Manousou S, Dahl L, Heinsbaek Thuesen B, Hulthen L, Nystrom Filipsson $\mathrm{H}$. Iodine deficiency and nutrition in Scandinavia. Minerva Med 2017; 108(2): 147-58. https://doi. org/10.23736/S0026-4806.16.04849-7.

12. Torlinska B, Bath S, Janjua A, Boelaert K, Chan S-Y. Iodine status during pregnancy in a region of mild-to-moderate iodine deficiency is not associated with adverse obstetric outcomes; Results from the Avon Longitudinal Study of Parents and Children (ALSPAC). Nutrients 2018; 10(3): 291. http://dx.doi. org/10.3390/nu10030291.

13. WHO. Assessment of iodine deficiency disorders and monitoring their elimination. A guide for programme managers. Geneva, Switzerland: World Health Organization, International Council for Control of Iodine Deficiency Disorders, United Nations Children's Fund; 2007.

14. Dahl L, Meltzer HM. The iodine content of foods and diets: Norwegian perspectives. In: Preedy VR, Burrow GN, Watson RR, eds. Comprehensive handbook of iodine. Nutritional, biochemical, pathological and therapeutic aspects. London: Academic Press; 2009, pp. 345-52.

15. Nerhus I, Wik Markhus M, Nilsen BM, Øyen J, Maage A, Ødegård ER, et al. Iodine content of six fish species, Norwegian dairy products and hen's egg. 2018; p. 62. Available from: https:// dx.doi.org/10.29219/fnr.v62.1291 [cited 25 May 2018].

16. Meltzer HM, Torheim LE, Brandsæter AL, Madar A, Abel MH, Dahl L. Risiko for jodmangel i Norge. Identifisering av et akutt behov for tiltak. Oslo, Norway: Nasjonalt råd for ernæring; 2016.
17. Lande B, Helleve A. Amming og spedbarns kosthold. Landsomfattende undersøkelse 2013. Oslo: The Norwegian Directorate of Health; 2013.

18. Kristiansen AL, Frost AL, Lande B. Diet among 2 year olds. National dietary survey - Småbarnskost. Oslo, Norway: The Norwegian Directorate of Health; 2009.

19. Nordic Council of Ministers. Nordic Nutrition Recommendations 2012: integrating nutrition and physical activity. 5 ed. Copenhagen: Nordisk Ministerråd; 2014, 627 p. http://dx.doi.org/10.6027/ Nord2014-002.

20. Henjum S, Lilleengen AM, Aakre I, Dudareva A, Gjengedal ELF, Meltzer HM, et al. Suboptimal iodine concentration in breastmilk and inadequate iodine intake among lactating women in Norway. Nutrients 2017; 9(7): 643. https://doi.org/10.3390/ nu9070643.

21. Brantsæter AL, Abel MH, Haugen M, Meltzer HM. Risk of suboptimal iodine intake in pregnant Norwegian women. Nutrients 2013; 5(2): 424-40. http://dx.doi.org/10.3390/nu5020424.

22. Henjum S, Aakre I, Lilleengen A, Garnweidner-Holme L, Borthne S, Pajalic Z, et al. Suboptimal iodine status among pregnant women in the Oslo Area, Norway. Nutrients 2018; 10(3): 280. http://dx.doi.org/10.3390/nu10030280.

23. Dahl L, Wik Markhus M, Sanchez P, Moe V, Smith L, Meltzer $\mathrm{H}$, et al. Iodine Deficiency in a study population of Norwegian pregnant women - results from the little in Norway Study (LiN). Nutrients 2018; 10(4): 513. https://doi.org/10.3390/nu10040513.

24. Abel MH, Caspersen IH, Meltzer HM, Haugen M, Brandlistuen $\mathrm{RE}$, Aase H, et al. Suboptimal maternal iodine intake is associated with impaired child neurodevelopment at 3 years of age in the Norwegian Mother and Child Cohort Study. J Nutr 2017; 147(7): 1314-24.https://doi.org/10.3945/jn.117.250456.

25. Brantsæter A, Knutsen H, Johansen N, Nyheim K, Erlund I, Meltzer $\mathrm{H}$, et al. Inadequate iodine intake in population groups defined by age, life stage and vegetarian dietary practice in a Norwegian convenience sample. Nutrients 2018; 10(2): 230. https://doi.org/10.3390/nu10020230.

26. Nerhus I, Odland M, Kjellevold M, Midtbø LK, Markhus MK, Graff IE, et al. Iodine status in Norwegian preschool children and associations with dietary sources of iodine - FINS-KIDS study. Eur J Nutr 2018: 1-9. https://doi.org/10.1007/s00394-018-1768-0.

27. Thomassen RA, Kvammen JA, Eskerud MB, Júlíusson PB, Henriksen C, Rugtveit J. Iodine status and growth in 0-2-year-old infants with cow's milk protein allergy. J Pediatr Gastroenterol Nutr 2017; 64(5): 806-11. doi: 10.1097/MPG.0000000000001434.

28. Fredriksen E, von Soest T, Smith L, Moe V. Parenting stress plays a mediating role in the prediction of early child development from both parents' perinatal depressive symptoms. J Abnorm Child Psychol 2018: 1-6. https://doi.org/10.1007/s10802-018-0428-4.

29. Norwegian Food Safety Authority, The Norwegian Directorate of Health, University of Oslo. The Norwegian food composition table. Oslo, Norway: Norwegian Food Safety Authority, The Norwegian Directorate of Health, University of Oslo; 2011.

30. IOM. Reference intakes for vitamin A, vitamin $\mathrm{k}$, arsenic, boron, chromium, copper, iodine, iron, manganese, molybdenum, nickel, silicon, vanadium and zinc: a report of the Panel on Micronutrients, Subcommittees on Upper Reference Levels of Nutrients and Interpretation and Uses of Dietary Reference Intakes, and the Standing Committee on the Scientific Evaluation of Dietary Reference Intakes. Washington, DC: Institute of Medicine; 2001.

31. Andersson M, De Benoist B, Delange F, Zupan J, Secretariat W. Prevention and control of iodine deficiency in pregnant 
and lactating women and in children less than 2-years-old: conclusions and recommendations of the technical consultation. Public Health Nutr 2007; 10(12): 1606. https://doi.org/10.1017/ S1368980007361004.

32. WHO. Global database on body mass index. BMI classification: World Health Organization; 2004. Available from: http://apps. who. int/bmi/index.jsp?introPage=intro_3.html [cited 29 May 2018].

33. WHO. WHO Anthro (version 3.2.2, January 2011) and macros 2011. Available from: http://www.who.int/childgrowth/software/ en/ [cited 20 May 2018].

34. WHO. WHO Child Growth Standards. Length/height-for age, weight-for -age, weight-for-length, weight-for-height and body mass index-for-age. Methods and development. Geneva, Switzerland: World Health Organization; 2006.

35. Skeaff SA, Ferguson EL, McKenzie JE, Valeix P, Gibson RS, Thomson CD. Are breast-fed infants and toddlers in New Zealand at risk of iodine deficiency? Nutrition 2005; 21(3): 325-31. https://doi.org/10.1016/j.nut.2004.07.004.

36. Andersson M, Aeberli I, Wüst N, Piacenza AM, Bucher T, Henschen I, et al. The Swiss iodized salt program provides adequate iodine for school children and pregnant women, but weaning infants not receiving iodine-containing complementary foods as well as their mothers are iodine deficient. $\mathbf{J}$ Clin Endocrinol Metab 2010; 95(12): 5217-24. https://doi. org/10.1210/jc.2010-0975

37. Fagt S, Gunnarsdottir I, Hallas-Møller T, Helldán A, Ingi Halldorsson T, Knutsen H, et al. Nordic dietary surveys: study designs, methods, results and use in food-based risk assessments. Copenhagen: Nordic Council of Ministers; 2012.

38. Norwegian Directorate of Health. Norwegian guidelines on diet, nutrition and physical activity. Oslo, Norway: Norwegian Directorate of Health; 2014.
39. Vandevijvere S, Mourri AB, Amsalkhir S, Avni F, Oyen HV, Moreno-Reyes R. Fortification of bread with iodized salt corrected iodine deficiency in school-aged children, but not in their mothers: a national cross-sectional survey in Belgium. Thyroid 2012; 22(10): 1046-53. https://doi.org/10.1089/thy. 2012.0016

40. Andersson M, Berg G, Eggertsen R, Filipsson H, Gramatkovski E, Hansson M, et al. Adequate iodine nutrition in Sweden: a cross-sectional national study of urinary iodine concentration in school-age children. Eur J Clin Nutr 2009; 63(7): 828-34. doi: 10.1038/ejen.2008.46.

41. Granfors M, Andersson M, Stinca S, Akerud H, Skalkidou A, Poromaa IS, et al. Iodine deficiency in a study population of pregnant women in Sweden. Acta Obstet Gynecol Scand 2015; 94(11): 1168-74. https://doi.org/10.1111/aogs.12713.

42. Trøan G, Dahl L, Margrete Meltzer H, Hope Abel M, Geir Indahl U, Haug A, et al. A model to secure a stable iodine concentration in milk. Food Nutr Res 2015; 59(1): 29829. https:// doi.org/10.3402/fnr.v59.29829.

43. WHO. Guiding principles for complementary feeding of the breastfed child. Geneva, Switzerland: World Health Organization; 2003.

44. Velasco I, Bath S, Rayman M. Iodine as essential nutrient during the first 1000 days of life. Nutrients 2018; 10(3): 290. http:// dx.doi.org/10.3390/nu10030290.

\footnotetext{
*Inger Aakre

Institute of Marine Research

PO. Box 2029 Nordnes

NO-5817 Bergen, Norway

Email: inger.aakre@hi.no
} 